\title{
Controlling Price-Responsive Heat Pumps for Overload Elimination in Distribution Systems
}

\section{Csetvei, Zsuzsa; Østergaard, Jacob; Nyeng, Preben}

Published in:

2nd Innovative Smart Grid Technologies Conference

Publication date:

2011

Link back to DTU Orbit

Citation (APA):

Csetvei, Z., Østergaard, J., \& Nyeng, P. (2011). Controlling Price-Responsive Heat Pumps for Overload Elimination in Distribution Systems. In 2nd Innovative Smart Grid Technologies Conference: Book of Conference proceedings IEEE. http://www.ieee-isgt-2011.eu/

\section{General rights}

Copyright and moral rights for the publications made accessible in the public portal are retained by the authors and/or other copyright owners and it is a condition of accessing publications that users recognise and abide by the legal requirements associated with these rights.

- Users may download and print one copy of any publication from the public portal for the purpose of private study or research.

- You may not further distribute the material or use it for any profit-making activity or commercial gain

- You may freely distribute the URL identifying the publication in the public portal

If you believe that this document breaches copyright please contact us providing details, and we will remove access to the work immediately and investigate your claim. 


\title{
Controlling Price-Responsive Heat Pumps for Overload Elimination in Distribution Systems
}

\author{
Zsuzsa Csetvei, Student Member, IEEE, Jacob Østergaard, Senior Member, IEEE, Preben Nyeng
}

\begin{abstract}
This paper investigates the possibility of applying electric heat pumps with the control-by-price-concept in order to avoid overload in a local distribution system. The proposed control algorithm is based upon a centrally dispatched real-time market price, reflecting the state of a larger power system, and is extended with a local price control for overload elimination on the corresponding feeder. The paper presents the mathematical models of a two-node system with price-responsive heat pumps, the chosen methodology of the central price calculation, and the proposed local feedback control architecture. The simulations of overload elimination have been carried out in Matlab. The results show the possibility of such auxiliary service by flexible units, which could be used for peak shaving in order to minimize the necessary oversizing of the power system components.
\end{abstract}

Index Terms - control-by-price, dynamic pricing, flexible demand, real-time market.

\section{INTRODUCTION}

$\mathrm{R}$ ENEWABLE energy sources (RES) are expected to increase their share in electricity generation because of political, economical and public intentions towards a society based on a non-polluting, sustainable, locally available energy supply. Besides the positive impacts of environmental friendly power generation, it is a technological challenge to increase the penetration of these usually intermittent energy sources in the power system, while keeping the quality and cost of power supply at the accustomed level. The increasing percentage of intermittent RES increases the minimum necessary regulating power, furthermore the share of controllable conventional power plants are decreasing. Therefore a new power system concept has been developed within the Smart Grid idea, where the power system balance is not only achieved by large generating units, but also distributed energy resources and small flexible loads would contribute. For such task the controlling of these adaptable units could be designed in a decentralized or centralized way with a direct or indirect control. As an indirect control the control-by-price concept has been proposed in [1]-[4]. The main concept is to integrate a real-time market into the existing electricity market structure, where the price is calculated according to the state of the system, and it is broadcasted with e.g. five-minute frequency to the flexible units, which are able to reschedule their power demand or supply according to the price signal [1], [4]. The adaptable

Zs. Csetvei, J. Østergaard and P. Nyeng are with the Centre for Electric Technology, Technical University of Denmark, Kgs. Lyngby, Denmark (e-mail: s090689@student.dtu.dk). loads could be consumers that can store energy in some form (e.g. electrical heating, cooling devices, electric vehicles), hence the customers do not need to decrease their energy demand and level of comfort, but the price-responsive devices can postpone their power demand and discharge their storage unit if the price is high and recharge when the price is low. In order to keep the relativity (high and low price) of the controlling signal, in [4] the usage of using non-dimensional relative prices has been proposed. In [5] and [6] the modelling of price-responsive heat pumps controlled by the mentioned relative price has been carried out.

However the appearance of new flexible price-responsive demands, such as electric heating, cooling, electric vehicles, might cause overload on the distribution system without upgrading it to increase its maximum transmittable power level. The reason for this is first of all the increased electricity demand because of replacing non-electric devices (e.g. fuel based heating, internal combustion engine vehicles) with electric consumers; and second of all because in areas with priceresponsive demands, these devices, controlled with fiveminute real time market price, might respond in a synchronized way to the variation of the price.

Therefore by following the five-minute relative price concept, we investigated the possibility of controlling the relative price locally to avoid overload on an electric line in a distribution system. The concept was to divide the distribution system into smaller consumer zones according to possible bottlenecks on power lines connecting these zones. Each zone has its price controller that receives the centrally dispatched real-time market price, and in case overloading was measured, the corresponding controller increases its zone-price with an additional price on the top of the market price. Therefore priceresponsive demands located in the zone are influenced to decrease their consumption, and thereby eliminate overload. Therefore upgrading the power system with price-responsive loads that are usually with high power consumption (e.g. electric heating, electric vehicles) could be possible without having to increase the power transmission capabilities of the power system excessively. Besides the main goals it also has to be a fair system for the customers and practical for communication and metering.

In section II the proposed market design, a price-responsive heat pump model and the relative real-time market price calculation method is presented, and the derived price control for overload elimination is described in details. In section III the results of line loading and relative price evolution are presented with and without overload elimination control. All models and simulations have been developed in Matlab. 


\section{MODELS FOR SIMULATION}

\section{A. Power System and Market Design}

A model of a low voltage radial system with two nodes, where each node is feeding a set of households with priceresponsive electric heat pump is assumed. As it is shown in Fig. 1, Node 1 is supplied from an infinite grid, and supplies Zone 1 and Node 2 via connection line L. Node 2 is only supplied by Node 1 and supplies Zone 2. The local, Z1 and Z2 price controllers are located at the feeder of each zone. The local price controller receives the real-time market price $\left(\mathrm{pr}_{\mathrm{RTM}}\right)$ each 5 minutes from the price server and computes the relative price $\left(\mathrm{pr}_{\mathrm{rel}}\right)$ for each second. The active power flow $\left(\mathrm{P}_{\mathrm{Z} 1}, \mathrm{P}_{\mathrm{Z} 2}\right)$ is measured at the feeders, averaged with a moving average over 30 seconds, and broadcasted to the local controller as well. In case overloading is detected, the local price controller modifies the one-second relative price, and the new local price $\left(\mathrm{pr}_{\mathrm{Z} 1}, \mathrm{pr}_{\mathrm{Z} 2}\right)$ is broadcasted to the corresponding zone in order to incite price-responsive loads to decrease and postpone their consumption.

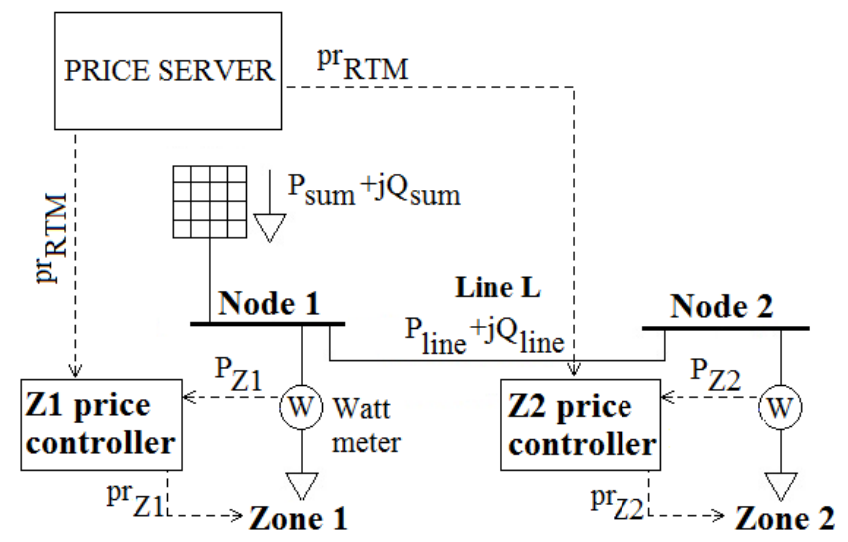

Fig. 1. Investigated two-node system with proposed price controlling and broadcasting hierarchy (dashed lines represents communication).

Each zone in Fig. 1 consists of households with priceresponsive heat pumps, where the electricity demand of each home was modelled as a sum of a constant base load, the electricity demand of the heat pump and a temporary peak load.

\section{B. Price-responsive electric heat pumps}

For the simulations the models and controlling method of the price-responsive heat pumps have been used from [5], [6] that are shortly summarized hereafter. The rated power and power consumption of each heat pump was calculated using the heat flow model shown in Fig. 2, where the task of the electric heating is to be able to keep the indoor air temperature around the set point. The parameters for the different properties, e.g. living area, or thermal masses $\left(\mathrm{C}_{\mathrm{A}}, \mathrm{C}_{\mathrm{H}}\right)$, were chosen randomly from statistical data of households in Denmark, while the ambient temperature $\left(\mathrm{T}_{\mathrm{O}}\right)$ was designed to vary according to a sinusoidal temperature profile within $5^{\circ} \mathrm{C}$ and $-5^{\circ} \mathrm{C}$ amplitudes, where the starting temperature for the simulation is $1^{\circ} \mathrm{C}$ and decreasing.

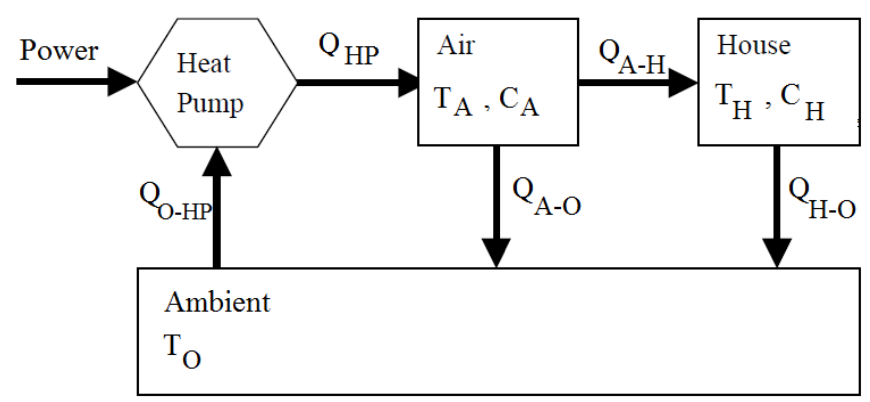

Fig. 2. Heat flow model of household: heat pumps utilize ambient heat (Q) with electrical power input (P) to heat up light (air) and heavy masses (house). Necessary input power depends on the thermal capacities (C), outdoor temperature $\left(\mathrm{T}_{0}\right)$ and indoor desired temperature [3].

The indoor temperature set points $\left(\mathrm{T}_{\mathrm{A}, \mathrm{set}}\right)$ of the households were distributed randomly between $20^{\circ}$ and $21^{\circ} \mathrm{C}$ with a $1{ }^{\circ} \mathrm{C}$ hysteresis control, where the price-responsive controller modifies the temperature set point with a varying delta-temperature offset $\left(\mathrm{T}_{\text {offset }}\right)$, as in (1). $\mathrm{T}_{\text {offset }}$ depends on the comfort settings of the customer $\left(\mathrm{k}_{\mathrm{p}}\right)$ and the changing relative price $\left(\mathrm{pr}_{\mathrm{rel}}\right)$, as it is computed in (2). Although the relative price is computed for each second at the local controller, the temperature setpoint of the heat pumps was designed to be updated each five minutes. Index i refers to the time step of the heat pump setpoint update loop. The relative price is derived by the method in [4] and is summarized in the following section.

$$
T_{A, \text { set new }, i}=T_{A, \text { set }}+T_{\text {offset }, i}
$$

$T_{\text {offset }, i}=-k_{p} \cdot p r_{r e l, i}$.

\section{Price Control}

The price signal at the local controller was derived from the sum of the relative price, reflecting the market prices, plus an extra price, reflecting the line overloading, if it was present, (3). Index $t$ refers to the time step of the price update loop at the local controller that was chosen to be one second, as explained later.

$$
p r_{Z 1, t}=p r_{\text {rel,t }}+p r_{\text {overload }, t}
$$

\section{1) Relative Price from Real Time Market}

In the proposed control system the real-time market absolute price is broadcasted each five-minute to the zone controller, from which the dimensionless five-minute relative price is computed by the method introduced in [4] from the current and past prices by (4)-(7). Thereafter the dimensionless onesecond relative price is derived by interpolation.

$p r_{r e l, i}=\frac{p r_{i}-p r_{a v g, i}}{p r_{d e v, i}}$

Where $p r_{i}$ is the absolute market price in five-minute loop $\mathrm{i}$; and $p r_{a v g, i}$, the average price and $p r_{d e v, i}$, the price deviation is calculated for each loop recursively.

$$
\begin{aligned}
& p r_{a v g, i}=p r_{a v g, i-1}+\frac{\Delta t}{\Delta t+\tau}\left(p r_{i}-p r_{a v g, i-1}\right) \\
& p r_{v a r, i}=p r_{v a r, i-1}+\frac{\Delta t}{\Delta t+\tau}\left(\left(p r_{i}-p r_{a v g, i}\right)^{2}-p r_{v a r, i-1}\right) \\
& p r_{d e v, i}=\sqrt[2]{p r_{v a r, i}}
\end{aligned}
$$


$\Delta \mathrm{t}$ is the five-minute time step between the price updates from the price server, and $\tau$ is a time constant, which determines how much and for high long a change in the absolute price affects the relative price. As it was investigated in [6], $\tau$ has been chosen to be 24 hours for controlling flexible space heating loads.

\section{2) Relative Price Control for Overload Elimination}

In order to reflect the line overloading in the price signal, and therefore modify the price-responsive heat pump loading by an indirect local control, a feedback control loop was designed for the local relative price calculation, Fig 3 . The relative price is altered with a PID controller each second according to the error signal $\left(P_{\text {error }}\right)$ that is the difference between the limitation and the averaged line loading. The moving averaging was applied on the line loading signal in order to avoid rapid changes in the controller response. In cases the line loading does not violate the limitation $\left(P_{\text {limit }}\right)$ the error signal is reset to zero in order to avoid controlling the line loading to the limitation reference point in non-congested intervals. During these cases the sum of the past errors $\left(P_{\text {error sum }}\right)$ are decreased gradually towards zero by another PID controller, depicted in the internal loop in Fig. 3, to reset the integral part of the controller, but to avoid rapid price changes right after line loading decreased below $P_{\text {limit }}$.

The price and the decreased new error sum is calculated according to (8) and (9) respectively in the controllers, where index $t$ refers to the one-second price update time step, and $d t$ is the one second delta time between two price updates. The synchronization of the price calculation loops are provided by the 'timer' block in Fig. 3. Although the price is calculated every second locally at the zone-controller, the heat pumps are designed to update their price-responsive temperature set point (1) once in a five minute time period. The reasons for this are the following: to keep the switching frequency of the heat pumps at a lower rate during its operation; lower computation rate of the controller, smaller necessary memory capacity and simpler metering devices for billing procedures compared to the one-second setpoint update. However simulation results showed oscillating line loading in case all the heat pumps in one zone received the same five-minute price at the same time. Therefore to avoid the synchronized response of the priceresponsive loads, the heat pumps react to the one-second prices at different times, in an equally distributed order with a time delay between each heat pump. A heat pump reacts to the broadcasted price when time $t$ in a five-minute loop is equal to the pre-defined timer of the heat pump $\left(t_{\mathrm{HP}, \mathrm{k}}\right)$, and keeps this price for the following five minutes, as it is defined in (10), where $k$ is the ordinal number of the heat pump in the zone.

$p r_{H P_{k}, t=\left[t_{H P, k} . t_{H P, k}+5 \mathrm{~min}\right]}=p r_{Z 1, t=t_{H P, k}}$

The procedure is illustrated in Fig. 4, which is the price distribution section of 'Heat Pumps / Price Timer' block in Fig.3. After the price distribution at time $t$, the heat pumps react to the new or old prices and the indoor air temperature, which results a new loading of the heat pumps and of the zone.

$$
\begin{aligned}
& p r_{Z 1, t}=p r_{r e l, t}+k_{p} \cdot P_{\text {error }, t}+k_{i} \cdot P_{\text {error sum }, t} \cdot d t+k_{d} \cdot\left[P_{\text {line }, t-1}-P_{\text {line }, t}\right] / d t, \\
& P_{\text {error sum }, t}=\operatorname{MIN}\left[0 ; P_{\text {error sum }, t-1}-k_{p} P_{\text {error sum }, t-1}-k_{i} P_{\text {error sum }, t} d t+\frac{k_{d} \cdot\left[P_{\text {line }, t-1}-P_{\text {line }, t}\right]}{d t}\right],
\end{aligned}
$$

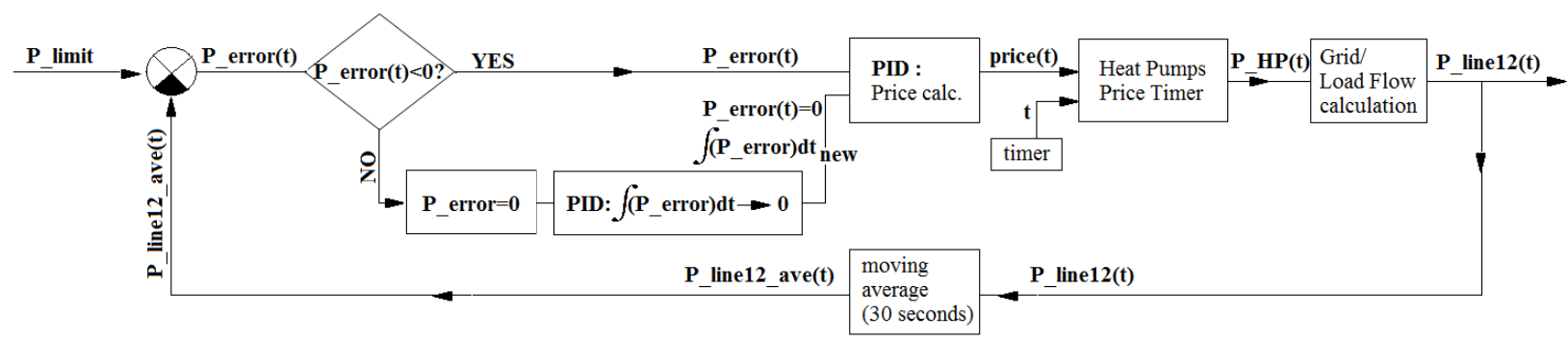

Fig. 3. Local feedback control loop for overload elimination. 


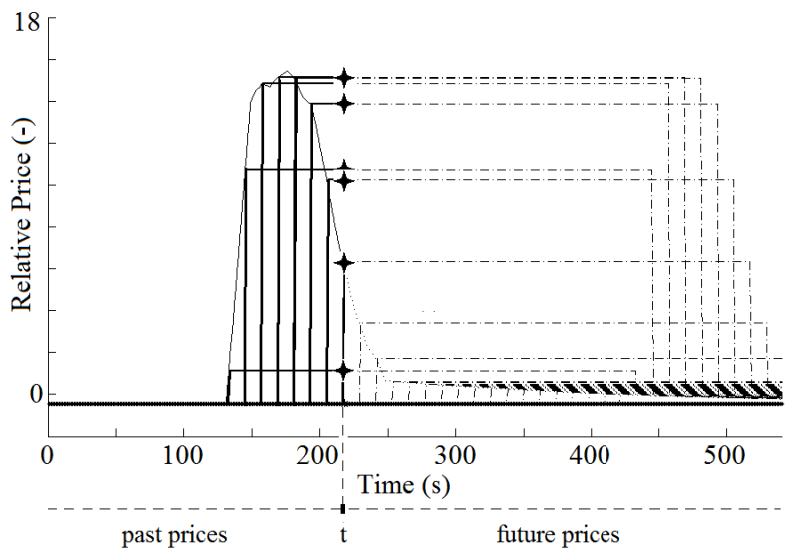

Fig. 4. Heat Pumps' five-minute price determination and distribution from one-second relative price: thick constant line represents the relative price calculated from the market; one-second relative price rise, depicted by thin solid line, shows the presence of overload. At time t the heat pumps were running with different prices, derived from previous or present relative prices, shown by star bullet points; solid and dashed 5 -min. prices are the received past and future prices of each heat pump before and after time $t$.

\section{RESULTS}

In this section the chosen system parameters and simulation results are presented. The absolute five-minute real time market prices were derived from the hourly electricity market prices of Western Denmark of 2009, from the day-ahead Elspot or the regulating market prices [7] by piecewise cubic Hermite interpolation.

The parameters of household loads are summarized in Table I. In Zone 2 the temporary peak load was present for a half an hour, and was sized to cause overload on the connection line $\mathrm{L}$ without overload elimination.

For the simulations three cases have been investigated: 1) in the most extreme case, the temporary peak load in Zone 2 was caused by increasing the consumption at several households simultaneously with a sum of $40 \mathrm{~kW}$ in a step function shape; 2) the demand is increased gradually, resulting in a sawtoothshaped loading up to $40 \mathrm{~kW} ; 3$ ) the overload is caused by low market prices and the corresponding response of priceresponsive heat pumps.

TABLE I

PARAMETERS OF HOUSEHOLD LOADINGS

\begin{tabular}{|c|c|c|}
\hline & Zone 1 & Zone 2 \\
\hline Number of Households & 25 & 25 \\
\hline Number of Heat Pumps & 25 & 25 \\
\hline Base load per household $(\mathrm{kW})$ & 0.2 & 0.2 \\
\hline Total base load per zone $(\mathrm{kW})$ & 5 & 5 \\
\hline Heat Pump capacity per household $(\mathrm{kW})$ & between 3.6 and 17.2 \\
\hline Total Heat Pump capacity in Zone (kW) & 272.9 & 272.9 \\
\hline Temporary peak load magnitude in zone (kW) & 0 & 40 \\
\hline Timing of peak loading (second) & - & {$[200 . .2000]$} \\
\hline Line loading limitation (kW) & \multicolumn{2}{|c}{90} \\
\hline
\end{tabular}

The load flow calculations have been carried out by the Newton-Raphson method with assuming a lossless line $\mathrm{L}$ with 0.08 $\Omega$ reactance and $0.064 \mathrm{~S}$ total line charging susceptance. The zone-loading was computed with a 30 second moving average for the local price controller. The gains of the two PID controllers are summarized in the Appendix, in Table II.

All the figures refer to Zone 2, where the overloading was caused and therefore the local control was in use. Note, the consumers of Zone 1 did not have a role in these simulations causing overload or eliminating it; however the presence of Zone 1 only represents the idea of the division of the low voltage grid into local price-control zones according to bottlenecks or radial feeders.

\section{A. Sudden $40 \mathrm{~kW}$ Step Function Peak Loading}

During a one-hour simulation the peak loading was present for a half an hour according to the parameters in Table I. Fig. 5 represents the loading of line L with local price control (solid line) and without (dashed line) local price control. Line loading without local control means $p r_{\text {overload }}=0$ in (3).

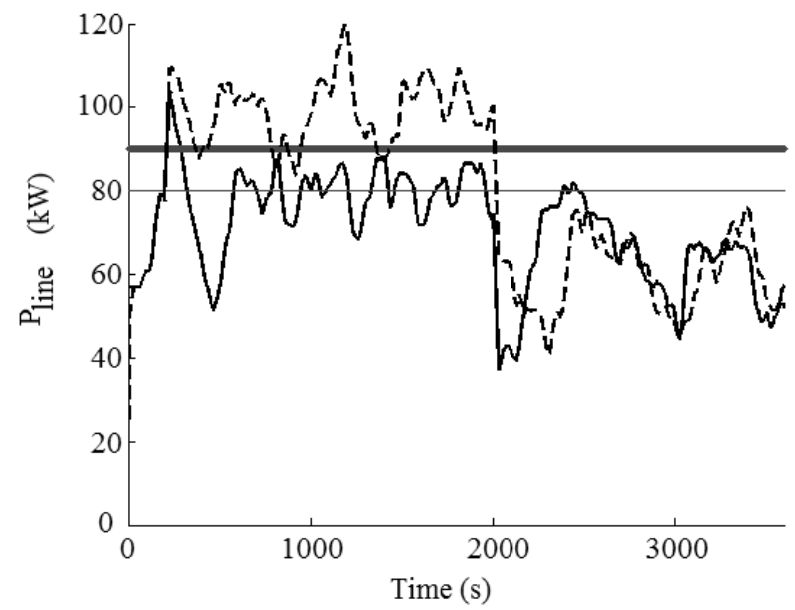

Fig. 5. Pline(t) active power flow on line $\mathrm{L}$ in case of a $40 \mathrm{~kW}$ step function shaped aggregated peak loading between [200..2000] seconds, with (solid line) and without (dashed line) local price control; constant line at $90 \mathrm{~kW}$ : line limitation; constant line at $80 \mathrm{~kW}$ : controller setpoint.

The figure shows that the controller decreased the active power flow below the line limitation (setpoint plus safety margin) in around 75 seconds after the overload occurred, and for the rest of the simulation the power demand was kept below $90 \mathrm{~kW}$. However it has to be noted that the controller setpoint had to be set below the real limitation of $90 \mathrm{~kW}$ (constant thick line) to $80 \mathrm{~kW}$ (constant thin line). For other simulation setups or power system networks, the necessary line limitation setpoint could be found empirically. Nevertheless it should be noted that short term over-currents can be acceptable until the power line reaches its thermal limitation.

Fig. 6 depicts the average value of the relative prices of each heat pump in descending order (black bars) and the average value of the relative prices calculated from the market price without overload elimination control (dashed line) during the time interval of the simulation. For this particular hour the results show large deviation of the household electricity 
costs from each other and from the real time market price. The absolute difference between the maximum and minimum average household price was 1.93 units.

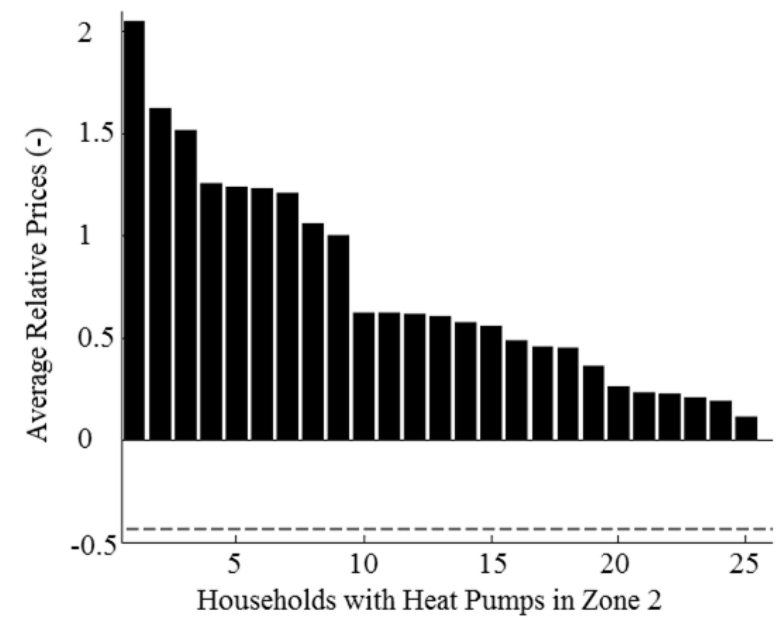

Fig. 6. Average value of relative prices of each heat pump in descending order (black bars) and average value of the relative electricity market prices (dashed line) during the investigated hour with step function shaped aggregated peak loading.

\section{B. Gradually Increased Peak Loading}

The results of the one-hour simulation with the more realistic gradually increased peak loading are presented in Fig. 7 and Fig. 8.

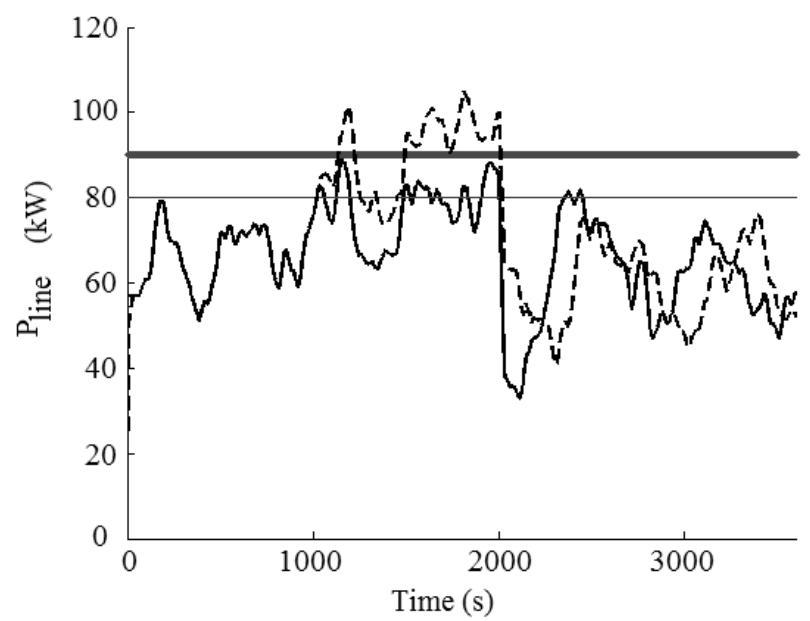

Fig. 7. Pline(t) on line $\mathrm{L}$ in case of a gradually increased sawtooth shaped aggregated peak loading is present between [200..2000 seconds], with (solid line) and without (dashed line) local price control.

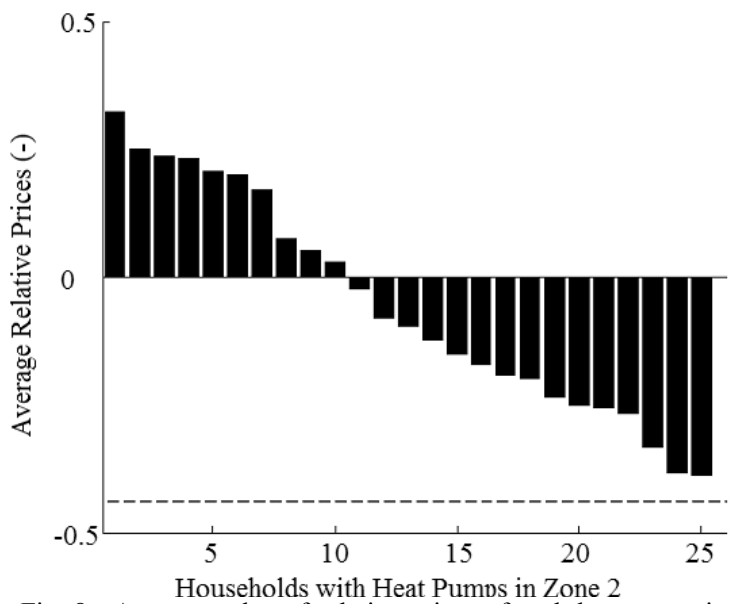

Fig. 8. Average value of relative prices of each heat pump in descending order (black bars) and average value of the relative market prices (dashed line) during the investigated hour, in case gradually increased peak loading was added.

Fig. 7 shows similar results as with the severe peak loading jump in Case III.A. However the differences between the average prices are decreased significantly, Fig. 8. The absolute difference between the maximum and minimum average household price was 0.71 units.

\section{Low Market Prices}

In case of an insufficiently sized power line, low price signals can cause overload due to the increased demand of the price-responsive units. This section investigates the possibility of resolving such cases by the local overload elimination price control, hence by increasing the centrally dispatched price signal locally. However due to socio-economic optimization, the price increase should be minimized, meanwhile fulfilling the task of overload elimination.

Results of a five-hour simulation are depicted in Fig. 9-13, where an additional peak loading was added between [200..2000] seconds as in case III.A, and with low relative market prices in the second half of the investigated time interval. Fig. 9 shows the relative prices from the market (thick continuous line) and the relative prices of all the heat pumps with local price control.

Fig. 10 represents the line loading in case the local price control was not implemented in the examined system. The first overloading was caused by the additional peak loading as in Case A, while the second continuous overloading was incited by the low market prices.

Fig. 11 depicts the line loading in case local price control was applied. For the time interval of the simulation the active power demand stayed below the line loading limitation setpoint. 


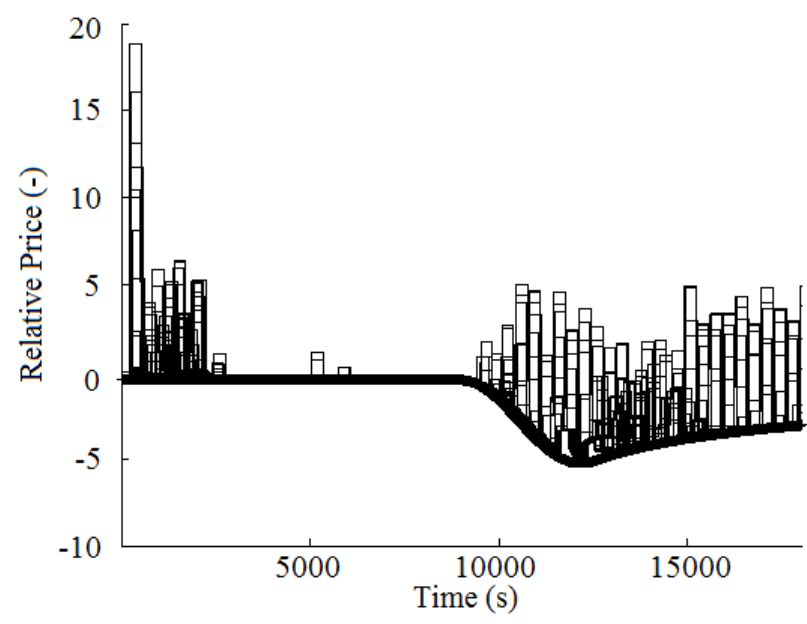

Fig. 9. Relative price from market (continuous thick line) and relative prices sent to all the heat pumps (fractional lines)

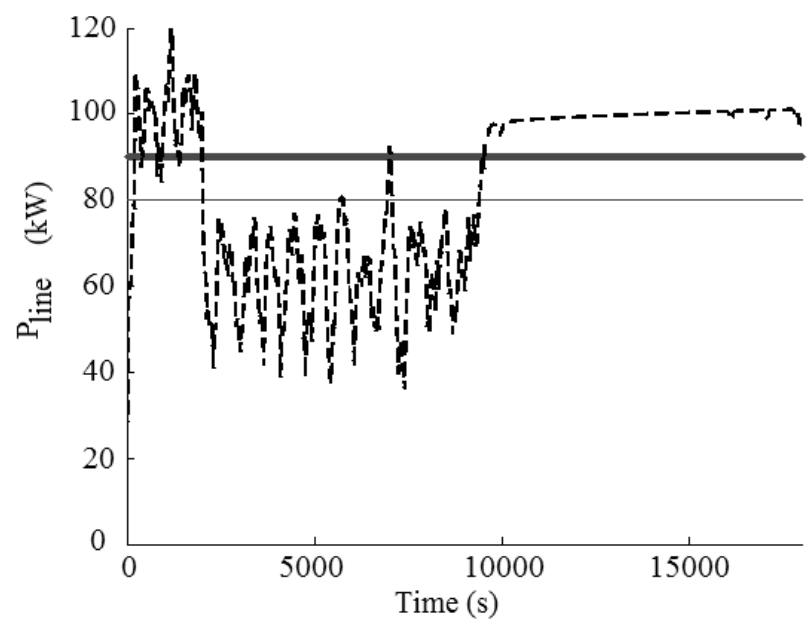

Fig. 10. Pline $(t)$, active power flow on line $\mathrm{L}$ with extra peak loading at [200..2000] second, and low market prices in the second half of simulation, without local price control.

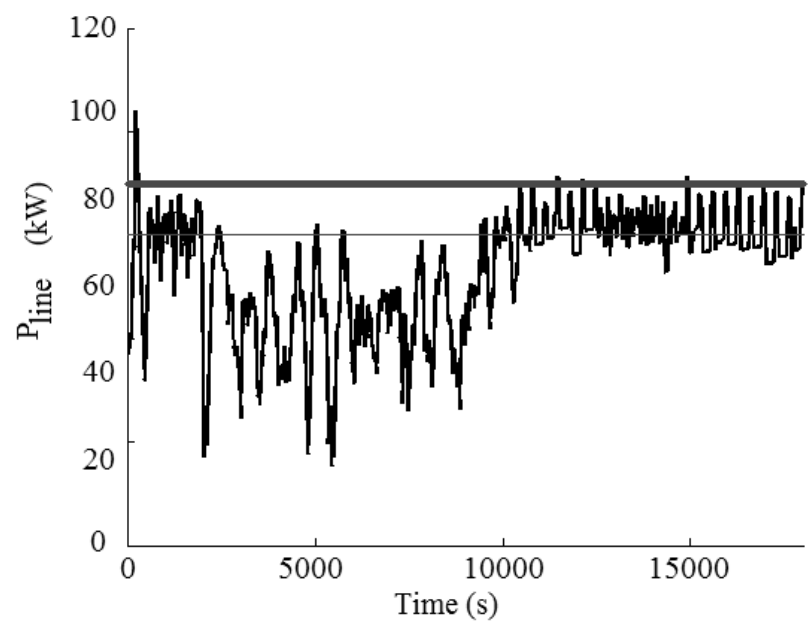

Fig. 11. Pline(t) as in Fig 10. but with overload elimination control. As Fig. 12 shows, for the five-hour time interval the deviation of the averaged electricity prices of each household are smaller compared to shorter simulation times. The absolute difference between the maximum and minimum average household price was 0.38 units.

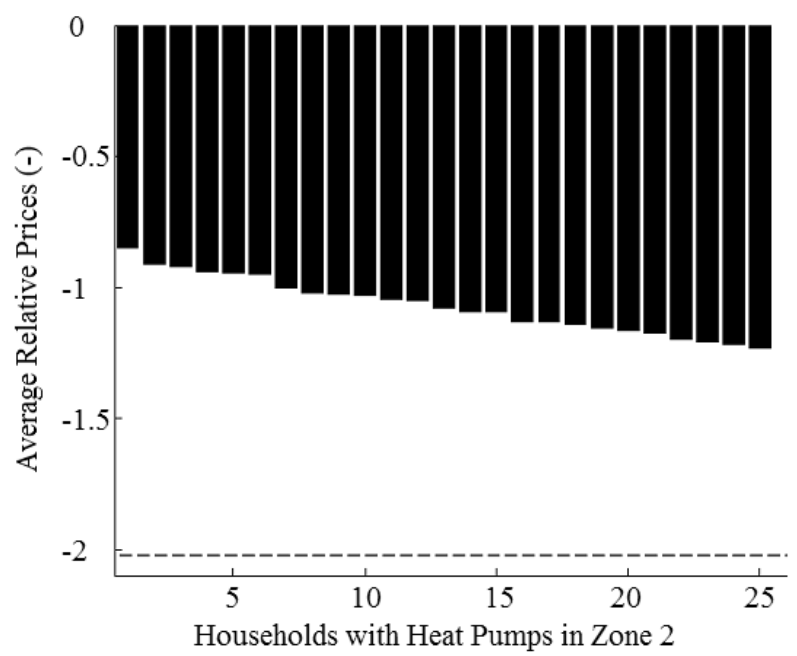

Fig. 12. Average value of relative prices of each heat pump in descending order (black bars) and average value of the relative market prices (dashed line) for the five-hour simulation case.

Fig. 13 depicts the average indoor air temperature of all the homes in Zone 2 (solid line) with the decreasing outdoor temperature (dashed line; according to Chapter II.B). It can be seen, that the average temperature is distorted by the varying relative price and line loading: the temperature sag between seconds [200..2000] was caused by the overload elimination; and the increased heating in the second half of the simulation was the result of the decreasing market prices. However the temperature was kept within acceptable limits.

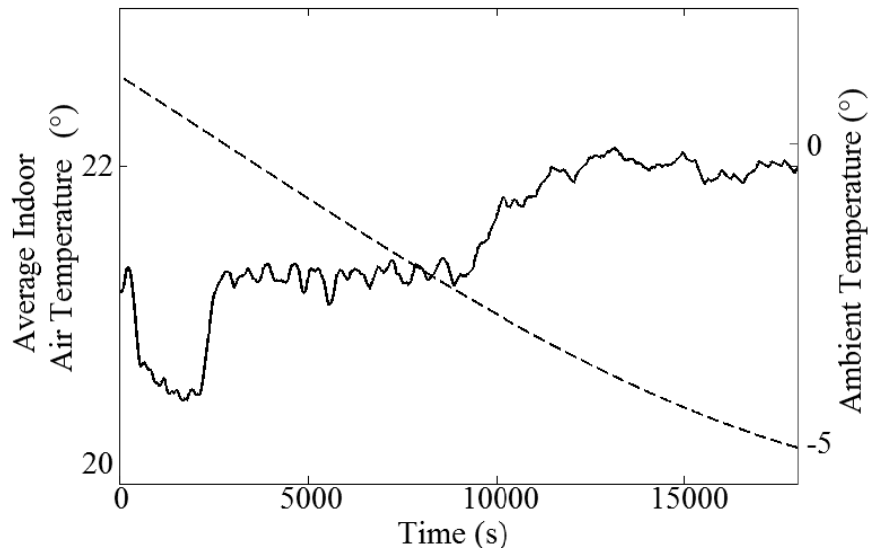

Fig. 13. Average of indoor air temperatures of all households (solid line) and sinusoidal ambient temperature (according to Chapter II.B) (dashed line) during the investigated 5 hours.

It should also be noted that usually a temperature drop due to high local prices will be followed by a rebound effect, when the heating device will try to recharge the missing energy, thus heat. The consumption is not to be decreased, but to be postponed. Also the temperature sag will usually be small as the thermal capacity of the house will keep it at an acceptable level for a certain amount of time. 


\section{DISCUSSION AND CONCLUSION}

In this paper we have designed a control architecture for local overload elimination by price-responsive heat pumps. The simulation results show the possibility of obtaining such auxiliary services by small flexible units on top of a centrally managed control-by-price concept. However, the results raise several technical challenges and economical, social questions for future investigations.

Furthermore the proposed method is based on the assumption that the five-minute pricing scheme would already exist over an extensive region with numerous price-responsive appliances on the balancing market. In this assumed smart grid of the future there could be several kind of appliances (e.g. refrigerators, electric vehicles or any other form of electric heating or cooling) complementing or replacing the response of the price-responsive heat pumps, which were the focus of this paper.

In the investigated system of this study we have observed the oscillating behaviour of price-responsive units with simultaneously broadcasted five-minute prices, therefore a onesecond local control loop have been implemented. However to minimize computational and switching requirements of the price-responsive units, each heat pump updates its temperature setpoint only once in a five-minute loop in a distributed order, following the previous unit with a time delay. In practice the time periods of the control-by-price concept, such as the fiveminute market price, five-minute appliance setpoint update (e.g. of heat pump) or the one-second local control loop could be designed with other time parameters and controller gains that match the overall behaviour of the price-responsive appliances installed, the constraints of the communication system and fulfils the control requirements.

In such "smart" distribution networks the investigated method could eliminate the overloading on the weak points of the grid by selecting the zones for local price control according to bottlenecks. Here the zone selection method assumed a radial system to achieve such services, which assumption is valid in present distribution systems at $10 \mathrm{kV}$ or below. If the method is to be expanded to higher voltage levels, it would have to be adapted to meshed networks, but the definition of zones would still rely on the bottlenecks.

The realization of the proposed method would therefore require detecting the bottlenecks in order to establish the zones; the measurement devices and local controllers would need to be installed; and the communication between the central price controller and households would have to be extended with the local controller.

In operation, ideally the local controller would derive the locational marginal prices (LMP) without having to know the supply and demand curves explicitly. To generate prices close to the LMP, which theoretically maximizes social welfare, the controllers need to be tuned empirically. Furthermore the method could be improved by implementing a self-learning price calculation that predicts the response of the consumers, and adopts its response forecast and price generation according to different outdoor temperatures, date of year, time of day etcetera.
On the other hand the proposed method would make the customers have to pay for the weakness of their local network, thus in practice not all customers may want to join the fiveminute pricing scheme. In such case if the local bottleneck cannot be eliminated because of the lack of customer participation, the corresponding power lines will have to be upgraded, which will need to be paid by the same customers of the distribution grid operator or owner. Therefore such grid company should be regulated in terms of what they do with the congestion rent and according to what is best for the customer: distribute the cost of line upgrading among customers, or localize the cost and control the consumption as in the investigated method. The fairness of such system should be assured by those who gain the right to make such decisions.

To sum up, we believe extending the centralized controlby-price concept with a decentralized, local control system could provide higher flexibility and efficiency of the power system by utilizing the price-responsive units to react locally and automatically to the state of the local grid.

\section{APPENDIX}

TABLE II PARAMETERS OF CONTROLLERS

\begin{tabular}{|c|c|c|c|}
\hline \multicolumn{1}{c|}{ PARAMETERS OF CONTROLLERS } \\
\hline $\begin{array}{c}\text { Controller } \\
\text { Price Calcu- } \\
\text { lator }\end{array}$ & $-8.0 \mathrm{e}-01$ & $-5.0 \mathrm{e}-04$ & $\mathrm{kd}$ \\
\hline $\begin{array}{c}\text { Error Sum } \\
\text { Limiter }\end{array}$ & $5.0 \mathrm{e}-03$ & $2.0 \mathrm{e}-06$ & $1.0 \mathrm{e}-06$ \\
\hline $\begin{array}{c}\text { Line loading } \\
\text { limitation } \\
\text { setpoint }\end{array}$ & \multicolumn{3}{|c|}{$\begin{array}{c}80 \mathrm{~kW} \\
(10 \mathrm{~kW} \text { safety margin to real line loading } \\
\text { limitation of } 90 \mathrm{~kW})\end{array}$} \\
\hline
\end{tabular}

\section{REFERENCES}

[1] F.C. Schweppe, R.D. Tabors, J.L. Kirtley Jr, H.R. Outhred, F.H. Pickel, " Homeostatic utility control, " IEEE Transactions on Power Apparatus and Systems, Vol. PAS-99, No.3, May-June 1980, pp. 1151-1163.

[2] F.L. Alvarado, "Is System Control Entirely by Price Feasible?," Proceedings of the $36^{\text {th }}$ Hawaii International Conference on System Science, 2003

[3] D. J. Hammerstrom et al., "Pacific Northwest GridWiseтм Testbed Demonstration Projects, Part I. Olympic Peninsula Project", National Technical Information Service, U.S. Department of Commerce, October 2007

[4] P. Nyeng, J. Østergaard, "Information and Communication Systems for Control-by-Price of Distributed Energy Resources and Flexible Demand," IEEE Transactions on Smart Grid, to be published.

[5] C. F. Mieritz, "Aggregate Modeling and Simulation of Price Responsive Heat Pumps," Master Thesis, Centre of Electric Technology, Technical Univ.Denmark, July 2010, [Online]. Available: http://www.dtu.dk/upload/centre/cet/studentprojects/10/cfm_msc_thesis.pdf

[6] P. Nyeng, "System integration of distributed energy resources - ICT, ancillary services, and markets," Ph.D. dissertation, Centre of Electric Technology, Technical Univ.Denmark, Feb. 2011, [Online]. Available: http://www.dtu.dk/centre/cet/English/research/projects/06-10/pny.aspx

[7] Energinet.dk, "Market data 2009," [Online]. Available: http://energinet.dk/EN/El/The-wholesale-market/Download-of-marketdata/Sider/default.aspx 


\section{BIOGRAPHIES}

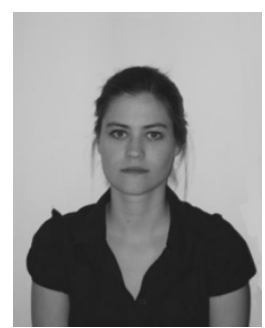

Zsuzsa Csetvei was born in 1986. She obtained the M.Sc degree in energy engineering in the Budapest University of Technology and Economics in 2009 in Hungary. Currently she is finishing her second M.Sc degree in wind energy in the Technical University of Denmark (DTU), Lyngby, Denmark in 2011. Her main field of interest is wind power integration into power systems.

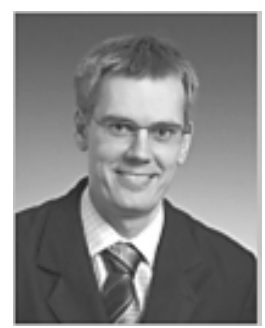

Jacob Østergaard (M'95-SM'09) obtained the M.Sc. degree in electrical engineering from the Technical University of Denmark (DTU), Lyngby, Denmark in 1995. He was with Research Institute of Danish Electric Utilities for 10 years where he did research within power system transmission and distribution and was responsible for developing industrial-academic collaboration. Since 2005 he has been Professor and Head of Centre for Electric Technology, DTU. His research interests cover SmartGrids with focus on system integration of renewable energy and distributed energy resources, control architecture for future power system, and flexible demand. Prof. Østergaard is serving in several professional organizations, boards and steering committees. He is head of the Danish experimental platform for electric power and energy, PowerLabDK, and he has been member of the EUSmartGrids advisory council. In 2009 he received the IBM Faculty Award.

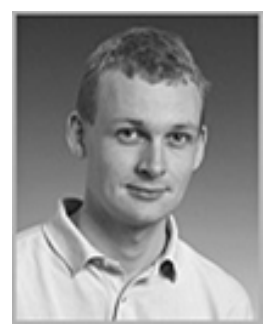

Preben Nyeng obtained the M.Sc. degree in industrial electrical engineering from the Technical University of Denmark (DTU), Lyngby, Denmark in 2000. He was with Logos Design A/S from 2000 to 2006, developing embedded hardware and software systems, and related database and communications systems. Since 2006 he has been with the Centre for Electric Technology at DTU, as a PhD student in the field of intelligent energy systems, and related information and communication technology. Mr. Nyeng is a member of CIGRE, the International Council On Large Electric Systems. 